Article

\title{
Facile and Efficient Syntheses of $(11 Z, 13 Z)$-Hexadecadienal and Its Derivatives: Key Sex Pheromone and Attractant Components of Notodontidae
}

\author{
Fu Liu®, Xiangbo Kong, Sufang Zhang and Zhen Zhang *
}

Key Laboratory of Forest Protection of National Forestry and Grassland Administration, Research Institute of Forest Ecology, Environment and Protection, Chinese Academy of Forestry, Beijing 100091, China; liufu2006@163.com (F.L.); xbkong@sina.com (X.K.); zhangsf@caf.ac.cn (S.Z.)

* Correspondence: zhangzhen@caf.ac.cn; Tel.: +86-010-6288-9567

Academic Editors: Martin C. Gruhlke and Alan J. Slusarenko

Received: 19 April 2019; Accepted: 6 May 2019; Published: 8 May 2019

\begin{abstract}
Syntheses of (11Z,13Z)-hexadecadienal (1), (11Z,13Z)-hexadecadienol (2), (11Z,13Z)-hexadecadien-1-yl acetate (3), and (Z)-13-hexadecen-11-ynal (4) from commercially available starting material 10-bromo-1-decanol are reported. These $(Z, Z)$-dienes and conjugated en-yne moieties are common in sex pheromone and attractant components for many Notodontide insect pests. The synthetic scheme, using the $\mathrm{C} 10+\mathrm{C} 3+\mathrm{C} 3$ strategy, was mainly based on three key steps: alkylation of lithium alkyne under a low temperature, cis-Wittig olefination of the aldehyde with propylidentriphenylphosphorane, and hydroboration-protonolysis of alkyne. This synthetic route provided $(11 Z, 13 Z)$-hexadecadienal (1) in a $23.0 \%$ total yield via an eight-step sequence, alcohol (2) in a 21.9\% total yield, acetate (3) in a 21.4\% total yield, and (Z)-13-hexadecen-11-ynal (4) in a $34.7 \%$ total yield. This simple strategy provides a new way to achieve syntheses of the key sex pheromones of Notodontide insect pests.
\end{abstract}

Keywords: sex pheromone; Notodontide; $(Z, Z)$-dienes; conjugated en-yne moieties; total synthesis

\section{Introduction}

Sex pheromones offer an environmentally-friendly alternative to control insect populations via mating disruption or other strategies in integrated pest management. Notodontidae (Lepidoptera, Noctuoidea) is a family of moths with approximately 3800 known species. Some Notodontids cause noticeable defoliation of their hosts, which causes serious ecological and economic losses [1].

Sex pheromones of ten species of Notodontid have been identified so far [2]. The main component of the sex pheromone of Oligocentria semirufescens is (Z)-dodec-7-en-1-ol, which is also attractive to the male moth of Schizura semirufescens [3]. The sex pheromone of Thaumetopoea bonjeani is a mixture of (11Z,13Z)-hexadecadienal (1) and (11Z,13Z)-hexadecadienol (2), and the ratio is 4:1 [4]. However, for another sympatric species, such as T. pityocampa, T. wilkinsoni, and T. processionea, (Z)-13-hexadecen-11-yn-1-yl acetate is the key sex pheromone candidate compound, and possesses a conjugated en-yne moiety with a $Z$ configuration, which is a new structure in the insect pheromone field [5-7]. In comparison, (Z)-13-hexadecen-11-ynal (4) is the sex pheromone component of Heterocampa guttivitta [8]. (11Z,13Z)-hexadecadienal (1) and (11Z,13Z)-hexadecadien-1-yl acetate (3) are the active sex pheromone ingredients of $N$. dromedaries and $N$. torva, respectively $[9,10]$. Trace-chemical reaction and coupled gas chromatography-mass spectrometry (GC-MS) analyses show that the active component of Clostera anastomosis is tetradecadienal [11]. 
Accordingly, most female-produced sex pheromones of Notodontid are normally complex mixtures of straight chain acetates, aldehydes, and alcohols, with 16 carbon atoms. This group of pheromones belongs to Type I, according to Ando's classification [12].

The structures of $(11 Z, 13 Z)$-hexadecadienal (1), (11Z,13Z)-hexadecadienol (2), and (11Z,13Z)-hexadecadien-1-yl acetate (3) contain a conjugated $(Z, Z)$-diene moiety. The construction of the $(Z, Z)$-conjugated diene system has been achieved in the past using a series of schemes: (1) the Wittig reaction: addition reaction of aldehyde with a $Z$ type-unsaturated enol [13]; (2) Cadiot-Chodkiewicz coupling coupled with hydroboration-protonolysis of 1,3-diyne [14]; (3) diimide reduction of acetylene and palladium-catalyzed coupling [15]; and (4) catalytic coupling of metal catalysts and hydroboration-protonolysis [16-22].

As for (Z)-13-hexadecen-11-ynal (4), it possesses a conjugated en-yne moiety of $Z$ configuration. The presently reported synthetic scheme for a conjugated en-yne moiety mainly includes: (1) the Wittig condensation of the propargylic aldehyde with propylidentriphenylphosphorane [23] and (2) cross-coupling of vinyl copper lithium with iodoalkynes [24].

Highly selective methods have to be employed for constructing the $(Z, Z)$-conjugated diene system and conjugated en-yne moiety of a $Z$ configuration, which exist in the structure of (11Z,13Z)-hexadecadienal (1) and (Z)-13-hexadecen-11-ynal (4), respectively. Furthermore, both (11Z,13Z)-hexadecadienal (1) and (Z)-13-hexadecen-11-ynal (4) possess the labile terminal formyl group, therefore the timing of placing the terminal formyl group is also important, owing to the fact that oxidation in the final step may isomerize the $(Z, Z)$-conjugated diene system [22]. The formyl group is introduced into its intermediate as acetal derivatives in an earlier stage of synthesis, which has been shown to avoid isomerization of the $(Z, Z)$-conjugated diene system from oxidation [17-20].

Consequently, we have successfully established a C10 + C3 + C3 synthetic strategy to efficiently obtain (11Z,13Z)-hexadecadienal (1), (11Z,13Z)-hexadecadienol (2), (11Z,13Z)-hexadecadien-1-yl acetate (3), and (Z)-13-hexadecen-11-ynal (4) together, using 1,1-diethoxy-10-iododecane (5), 13,13-diethoxytridec-2-ynal (6), and (Z)-16,16-diethoxyhexadec-3-en-5-yne (7) as the key building blocks, employing the alkylation of lithium alkyne, electrolytic manganese dioxide oxidation, cis-Wittig olefination reaction, and hydroboration-protonolysis as the key reactions.

\section{Results and Discussion}

As Scheme 1 shows, the retrosynthesis was based on the alkylation of lithium alkyne, a cis-Wittig olefination reaction, and hydroboration-protonolysis, namely a C10 + C3 + C3 strategy. The two C3 synthons were easily obtained, and the C10 subunit was a protected iodoalkane (5), which could be prepared from 10-bromo-1-decanol. 
<smiles>[R]OCC(C)(C)C=CC=CCC</smiles>

Hydroboration-protonolysis<smiles>CCC=CC#CCC(C)OCC</smiles>

7 cis-Wittig reaction<smiles>[CH2+]CCC[SnH2]Br</smiles>

$$
\begin{aligned}
& \mathrm{R}=\mathrm{CHO} \quad 1 \\
& \mathrm{CH}_{2} \mathrm{OH} 2 \\
& \mathrm{CH}_{2} \mathrm{COCH}_{3} 3
\end{aligned}
$$<smiles>CCOC(CC#CC=O)OCC</smiles>

6
C3

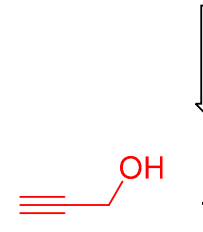

C3

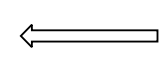<smiles>CCC=CC#CCC=O</smiles>

Alkylation of lithium alkyne
5 (C10)<smiles>C=CCCBr</smiles>

Scheme 1. Structures and retrosynthetic analysis of (11Z,13Z)-hexadecadienal (1), (11Z,13Z)-hexadecadienol (2), (11Z,13Z)-hexadecadienyl acetate (3), and (Z)-13-hexadecen-11-ynal (4), the key sex pheromones of Notodontidae.

Scheme 1 shows the synthetic plan for $(11 Z, 13 Z)$-hexadecadienal $(\mathbf{1})$ and its derivatives. cis-Wittig olefination of 13,13-diethoxytridec-2-ynal (6) with propylidentriphenylphosphorane will give the required carbon-skeleton as (Z)-16,16-diethoxyhexadec-3-en-5-yne (7), whose deprotection will give (Z)-13-hexadecen-11-ynal (4), and reduction and deprotection will give (11Z,13Z)-hexadecadienal 1 and its derivatives ( 2 and 3 ). The two $\mathrm{C} 3$ synthons are commercially available, while the $\mathrm{C} 10$ subunit (5) can be prepared from 10-bromo-1-decanol.

The facile and efficient synthesis of (11Z,13Z)-hexadecadienal (1), (11Z,13Z)-hexadecadienol (2), (11Z,13Z)-hexadecadienyl acetate (3), and (Z)-13-hexadecen-11-ynal (4) is summarized in Scheme 2. 


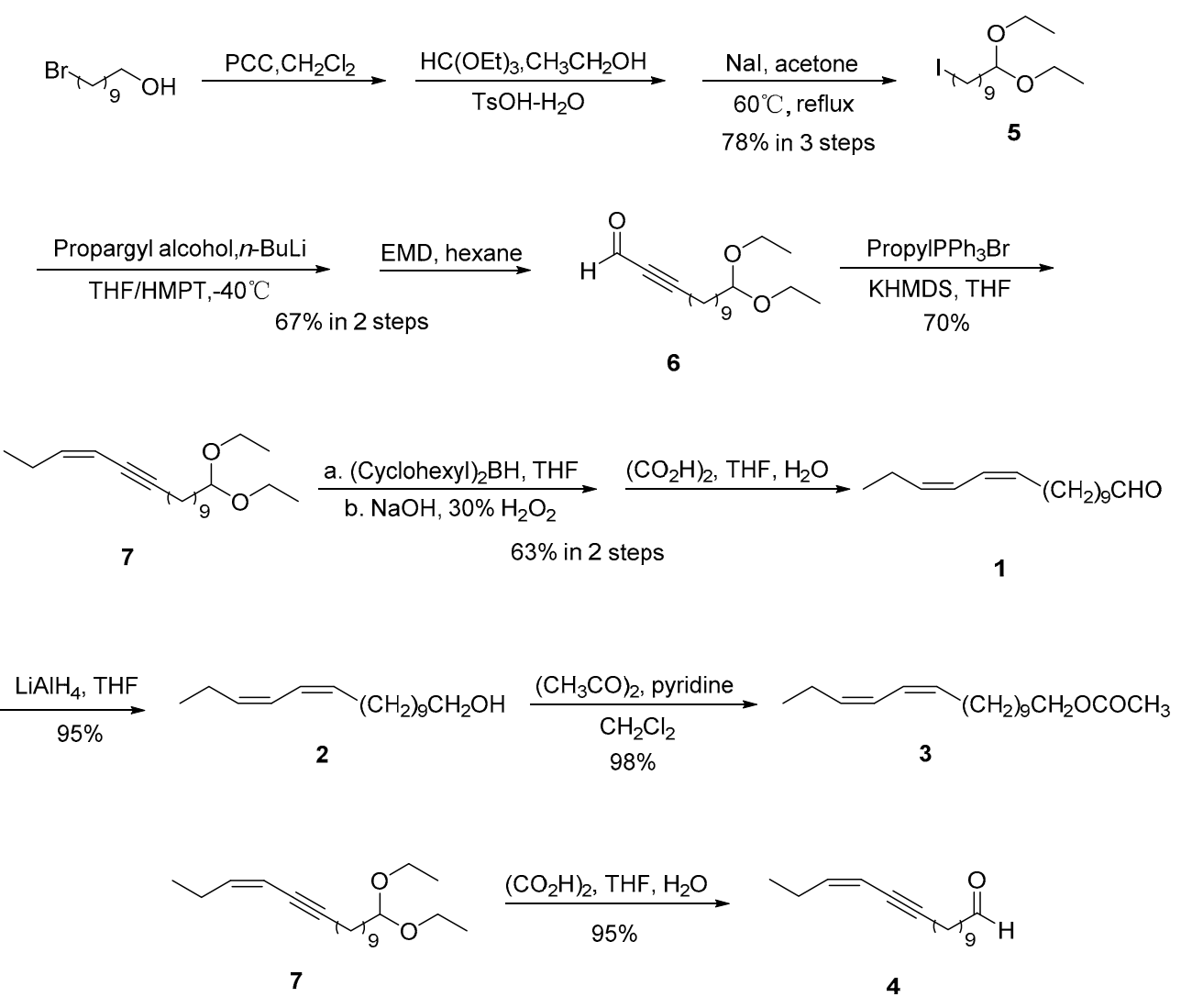

PCC: pyrindium chlorochromate; HMPT: hexamethyl phosphoric triamide; EMD: electrolytic manganese dioxide; KHMDS: potassium bis(trimethylsilyl)amide

Scheme 2. Synthesis of (11Z,13Z)-hexadecadienal (1), (11Z,13Z)-hexadecadienol (2), (11Z,13Z)-hexadecadienyl acetate (3), and (Z)-13-hexadecen-11-ynal (4).

Commercially available 10-bromo-1-decanol was chosen as the starting material. 1,1-diethoxy-10-iododecane (5) could be obtained in three steps according to Furber's method [20]. First, 10-bromo-1-decanol was oxidized using pyrindium chlorochromate in $\mathrm{CH}_{2} \mathrm{Cl}_{2}$ at room temperature for $3 \mathrm{~h}$. The clean formation of aldehyde was treated with triethylorthoformate and $p$-toluenesulfonic acid in anhydrous ethanol. Following this, the crude product was refluxed with $\mathrm{NaI}$ in anhydrous acetone until the end of the halogen exchange reaction $(4 \mathrm{~h})$. The yield of 5 was $78 \%$ based on 10-bromo-1-decanol.

Alkynes alkylation is widely used in the synthesis of terminal alkynes and alkynols [22,25-27], especially sex pheromones of insect pests [28-30]. At the condition of $-40{ }^{\circ} \mathrm{C}$ under argon, alkylation of lithium propargyl alcohol (C3 synthon) with 1,1-diethoxy-10-iododecane (5) in tetrahydrofuran/hexamethyl phosphoryl triamide furnished the acetylenic compound.

It is well-known that activated manganese dioxide is a useful reagent for the oxidation of unsaturated alcohols to corresponding aldehyde. However, its quality varies widely, the preparation is tedious, and the commercial reagent is expensive. Electrolytic manganese dioxide (EMD) is less expensive and does not require purification [31]. The application of EMD would provide a good option for sex pheromones syntheses. Treatment of the acetylenic compound with excess electrolytic manganese dioxide (30 eq) in hexane at room temperature for $2 \mathrm{~h}$, led to the clean formation of the expected alkynal 6 in a $67 \%$ yield based on 5 .

Wittig reactions are most commonly used to couple aldehydes to singly-substituted phosphine ylides. Unstabilized ylides, mainly via the erythro betaine intermediate, lead to the Z-alkene product $[29,32,33]$. The carbonyl olefination of the alkynal 6 with phosphorus ylides is 
a general method for the preparation of Z-enyne 7. To ensure the cis selectivity of Wittig olefination, potassium bis(trimethylsilyl)amide was chosen as the base. The ylide, prepared from n-propyl triphenylphosphonium bromide via a reaction with potassium bis(trimethylsilyl)amide as the base, in a stoichiometric ratio of reagents, reacted with 6 in THF at $-70{ }^{\circ} \mathrm{C}$ to give (Z)-16,16-diethoxyhexadec-3-en-5-yne (7). Pure product 7 was isolated from the reaction mixture using column chromatography in a good yield $(70 \%)$.

Z-selective reduction of the triple bond was a challenge in the synthesis of the sex pheromones. Bercot et al. employed selective catalytic hydrogenation, generally using a Lindlar catalyst [34], but the pretreatment of calcium carbonate carriers is rarely reported. Khrimian et al. first employed zinc activated with copper and silver in cis reduction of the conjugated trienynes in pheromone synthesis [35]. Unfortunately, pretreatment of the active Zn reagent is complicated and time-consuming. Hungerford and Kitching applied titanium (II) to finish the triple reduction [36]. However, the reduction gave additional products generated via the 1,4-reduction of the en-yne. As previously reported, 3-4 equivalents of alkylborane in THF are necessary to effectively complete hydroboration of the triple bond [14,22]. The reaction system was treated with acetic acid to achieve protonolysis. Oxidation of the resulting dicyclohexylborinate was achieved via the addition of aqueous sodium hydroxide followed by the dropwise addition of hydrogen peroxide. The crude product contained $\mathbf{1}$ as well, which was liberated in the course of protonolysis with acetic acid. In addition, without purification, the mixture was dissolved in THF and treated with aqueous oxalic acid to deprotect the acetal moiety and give $\mathbf{1}$ in a $63 \%$ yield based on 7 .

The compound 1 was cleanly converted into the corresponding alcohol 2 in a 95\% isolated yield by reduction with $\mathrm{LiAlH}_{4}$ in THF under argon.

(11Z,13Z)-hexadecadienyl acetate (3) was easily prepared from (11Z,13Z)-hexadecadienol (2), acetic anhydride, and pyridine in $\mathrm{CH}_{2} \mathrm{Cl}_{2}$ in a yield $98 \%$.

(Z)-16,16-diethoxyhexadec-3-en-5-yne (7) was dissolved in THF and treated with aqueous oxalic acid to deprotect the acetal moiety and give (Z)-13-hexadecen-11-ynal (4) in a 95\% yield.

\section{Materials and Methods}

\subsection{Chemistry}

\subsubsection{General Method}

All commercially available reagents were used without further purification. THF was distilled from sodium. $\mathrm{CH}_{2} \mathrm{Cl}_{2}$ was distilled from $\mathrm{CaH}_{2}$. Column chromatography was performed on silica gel

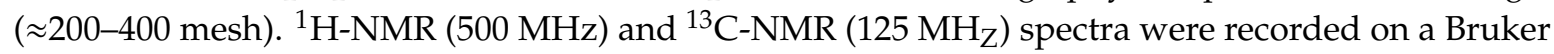
NMR spectrometer (Bruker, Fällanden, Switzerland). The component analysis was carried out using an Agilent gas chromatograph coupled with a mass spectrometry system (TRACE GC 2000). The GC was equipped with a polar HP-5MS column $(30 \mathrm{~m} \times 0.25 \mathrm{~mm} \times 0.25 \mu \mathrm{m}$, Agilent Technologies, Wilmington, $\mathrm{DE}, \mathrm{USA}$ ) and included an injector temperature set to $230^{\circ} \mathrm{C}$. The oven temperature for the HP-5MS GC column was initially programmed at $60{ }^{\circ} \mathrm{C}$ for one minute and then subsequently increased to $280{ }^{\circ} \mathrm{C}$ at $8^{\circ} \mathrm{C}$ per minute. Helium was used as the carrier gas. The GC data for compounds 1, 2, 3, 4, and NMR spectra for all synthetic compounds were list in the supplementary materials.

\subsubsection{General Procedure for the Synthesis of Compounds}

1,1-Diethoxy-10-iododecane (5): 10-Bromodecanol (50 g, $210 \mathrm{mmol}$ ) was oxidized using pyridinium chlorochromate $(90.5 \mathrm{~g}, 420 \mathrm{mmol})$ in $\mathrm{CH}_{2} \mathrm{Cl}_{2}(800 \mathrm{~mL})$ at room temperature for $3 \mathrm{~h}$. The organic layer was filtered, and the residual was washed with petroleum. Removal of the solvent from the combined organic layers in vacuo gave a dark oil. The dark-colored residue was chromatographed over $\mathrm{SiO}_{2}$, and elution with hexane/EtOAc $(30: 1, v / v)$ gave crude 10-bromodecanal. 
Triethyl orthoformate $(44.5 \mathrm{~g}, 300 \mathrm{mmol})$ and $p$-sulphonic acid monohydrate $(0.57 \mathrm{~g}, 3 \mathrm{mmol})$ were added to a stirred and ice-cooled solution of the crude 10-bromodecanal in anhydrous ethanol $(300 \mathrm{~mL})$. After the exothermic reaction had subsided, the mixture was left at $0{ }^{\circ} \mathrm{C}$ overnight. Water was then added, and the mixture was made basic by adding $\mathrm{K}_{2} \mathrm{CO}_{3}$ solution. The mixture was extracted with diethyl ether, and then washed with brine and dried over $\mathrm{MgSO}_{4}$. The solvent was removed under reduced pressure and the product was chromatographed on silica (hexane/EtOAc $(25: 1, v / v))$, which gave crude 1,1-diethoxy-10-bromodecanal.

This product was converted into the title iodide by being stirred for $4 \mathrm{~h}$ with sodium iodide (90 g, $600 \mathrm{mmol})$ in dry acetone $(500 \mathrm{~mL})$ under reflux. The solvent was removed under reduced pressure, the mixture was diluted with water $(200 \mathrm{~mL})$, and the product was extracted with petroleum. The extracts were washed with water, $1 \% \mathrm{Na}_{2} \mathrm{~S}_{2} \mathrm{O}_{3}$ solution, and brine; dried over $\mathrm{Na}_{2} \mathrm{SO}_{4}$; and concentrated under reduced pressure. The resulting residue was chromatographed over $\mathrm{SiO}_{2}$. Elution with hexane/EtOAc $(25: 1, v / v)$ was conducted to yield 1,1-diethoxy-10-iododecan (5) as an oil (58.8 g, 78\% yield based on 10-bromodecanol); ${ }^{1} \mathrm{H}-\mathrm{NMR}\left(500 \mathrm{MHz}, \mathrm{CDCl}_{3}\right) \delta 1.21(6 \mathrm{H}, \mathrm{t}, \mathrm{J}=7.0 \mathrm{~Hz})$, $1.29(12 \mathrm{H}, \mathrm{m}), 1.60(2 \mathrm{H}, \mathrm{m}), 1.82(2 \mathrm{H}, \mathrm{m}), 3.19(2 \mathrm{H}, \mathrm{t}, \mathrm{J}=7.0 \mathrm{~Hz}), 3.49(2 \mathrm{H}, \mathrm{m}), 3.64(2 \mathrm{H}, \mathrm{m}), 4.48(1 \mathrm{H}, \mathrm{t}$, $J=6.0 \mathrm{~Hz}) ;{ }^{13} \mathrm{C}-\mathrm{NMR}\left(125 \mathrm{MHz}, \mathrm{CDCl}_{3}\right) \delta 102.9,60.8,60.8,33.6,33.5,30.5,29.4,29.4,29.3,28.5,24.7$, $13.4,15.4,7.3$.

13,13-Diethoxytridec-2-ynal (6): $n$-Butyllithium (2.5 M in hexane) (160 mL, $400 \mathrm{~mol}$ ) was added slowly to a solution of propargyl alcohol (11.2 g, $200 \mathrm{~mol})$ in HMPT/THF $(1: 1, v / v, 800 \mathrm{~mL})$ at $-40^{\circ} \mathrm{C}$ under argon, and the solution was stirred for $30 \mathrm{~min}$. A solution of 1,1-diethoxy-10-iododecan (5) (35.6 g, $100 \mathrm{mmol})$ in HMPT/THF (1:1, v/v, $50 \mathrm{~mL})$ was then added over $20 \mathrm{~min}$. After being stirred overnight at the same temperature $\left(-20{ }^{\circ} \mathrm{C}\right)$, the reaction mixture was quenched with water and extracted with ethyl acetate. The organic layer was washed with water and dried with $\mathrm{Na}_{2} \mathrm{SO}_{4}$. Evaporation left the crude product.

An excess of electrolytic manganese dioxide $(52.1 \mathrm{~g}, 600 \mathrm{mmol})$ was added to a solution of the crude product $(17.0 \mathrm{~g})$ in dry hexane $(300 \mathrm{~mL})$. The mixture was stirred at room temperature for $4 \mathrm{~h}$, and the residues containing manganese were filtered off. The yield of the protected alkenal 6 after chromatography was 67\% (15.7 g) in two steps. ${ }^{1} \mathrm{H}-\mathrm{NMR}\left(500 \mathrm{MHz}, \mathrm{CDCl}_{3}\right) \delta 1.19-1.26(6 \mathrm{H}, \mathrm{m})$, 1.29-1.30 (12H, m), $1.40(2 \mathrm{H}, \mathrm{m}), 1.58-1.63(2 \mathrm{H}, \mathrm{m}), 2.40-2.43(2 \mathrm{H}, \mathrm{m}), 3.46-3.52(2 \mathrm{H}, \mathrm{m}), 3.61-3.67(2 \mathrm{H}$, $\mathrm{m}), 4.48(1 \mathrm{H}, \mathrm{t}, J=6.0 \mathrm{~Hz}), 9.77(1 \mathrm{H}, \mathrm{t}, J=1.5 \mathrm{~Hz}) ;{ }^{13} \mathrm{C}-\mathrm{NMR}\left(125 \mathrm{MHz}, \mathrm{CDCl}_{3}\right) \delta 177.1,102.8,91.4,75.6$, $60.5,60.5,33.5,29.3,29.3,29.2,29.0,28.8,28.7,24.6,18.5,15.2,15.2$.

(Z)-16,16-diethoxyhexadec-3-en-5-yne (7): n-propyl triphenylphosphonium bromide ( $23.1 \mathrm{~g}, 60 \mathrm{mmol})$ in THF $(150 \mathrm{~mL})$ was added to a solution of potassium bis(trimethylsilyl)amide $(0.5 \mathrm{M}$ in toluene, $140 \mathrm{~mL}, 70 \mathrm{mmol})$. After refluxing for $1 \mathrm{~h}$, the reaction mixture was cooled to $-70{ }^{\circ} \mathrm{C}$, and a solution of the aldehyde $6(14.1 \mathrm{~g}, 50 \mathrm{mmol})$ in THF $(20 \mathrm{~mL})$ was added dropwise. The mixture was then stirred for $3 \mathrm{~h}$, before it was poured into aqueous $\mathrm{NH}_{4} \mathrm{Cl}(10 \%, 30 \mathrm{~mL})$. The organic phase was separated and the aqueous phase was extracted with hexane. The combined organic phases were dried with $\mathrm{Na}_{2} \mathrm{SO}_{4}$. After evaporation, the crude product was subjected to medium-pressure column chromatography (30:1, $v / v)$, yielding 70\% (10.8 g). ${ }^{1} \mathrm{H}-\mathrm{NMR}\left(500 \mathrm{MHz}, \mathrm{CDCl}_{3}\right) \delta 1.01(3 \mathrm{H}, \mathrm{t}, J=7.5 \mathrm{~Hz}), 1.20(6 \mathrm{H}, \mathrm{t}, J=7.0 \mathrm{~Hz})$, $1.29(12 \mathrm{H}, \mathrm{m}), 1.51-1.55(2 \mathrm{H}, \mathrm{m}), 1.59-1.63(2 \mathrm{H}, \mathrm{m}), 2.28-2.35(4 \mathrm{H}, \mathrm{m}), 3.49(2 \mathrm{H}, \mathrm{m}), 3.64(2 \mathrm{H}, \mathrm{m})$, $4.48(1 \mathrm{H}, \mathrm{t}, J=6.0 \mathrm{~Hz}), 5.40(1 \mathrm{H}, \mathrm{m}), 5.80(1 \mathrm{H}, \mathrm{m}) ;{ }^{13} \mathrm{C}-\mathrm{NMR}\left(125 \mathrm{MHz}, \mathrm{CDCl}_{3}\right) \delta 144.0,108.7,102.9$, $94.5,77.2,60.8,60.8,33.6,29.5,29.5,29.4,29.1,28.9,28.8,24.7,23.4,19.5,15.3,15.3,13.4$.

(11Z,13Z)-hexadecadienal (1): A solution of compound 7 (6.2 g, $20 \mathrm{mmol})$ in THF (10 mL) was added dropwise to the above dicyclohexylborane solution $(42 \mathrm{mmol})$ at $-20{ }^{\circ} \mathrm{C}$. The suspension was stirred at approximately $-15^{\circ} \mathrm{C}$ for $2 \mathrm{~h}$ and then allowed to reach room temperature. After $2 \mathrm{~h}$ of stirring at room temperature, the precipitate of dicyclohexylborane had disappeared. Glacial acetic acid $(5 \mathrm{~mL})$ was then added to the mixture, which was stirred for $2 \mathrm{~h}$ at $50{ }^{\circ} \mathrm{C}$. Oxidation of the resulting dicyclohexylborinate was achieved by the addition of sodium hydroxide $(6 \mathrm{M}, 6 \mathrm{~mL})$ followed by the dropwise addition of hydrogen peroxide $(35 \%, 7 \mathrm{~mL})$. The mixture was stirred for an additional $30 \mathrm{~min}$ and was then poured into ice-water $(15 \mathrm{~mL})$, extracted with hexane, and dried $\left(\mathrm{MgSO}_{4}\right)$. 
After evaporation, a solution of the crude product in tetrahydrofuran $(30 \mathrm{~mL})$ was added to a solution of oxalic acid dihydrate $(3.0 \mathrm{~g})$ in water $(30 \mathrm{~mL})$. The mixture was stirred and heated for $40 \mathrm{~min}$ at $60{ }^{\circ} \mathrm{C}$ under argon. Then, the mixture was extracted with hexane. The organic solution was washed with water, a sodium hydrogen carbonate solution, and brine; dried $\left(\mathrm{Na}_{2} \mathrm{SO}_{4}\right)$; and concentrated in vacuo. The residue was chromatographed over $\mathrm{SiO}_{2}$ with hexane/EtOAc $(20: 1, v / v)$, which gave $1(3.0 \mathrm{~g}, 63 \%)$ as a colorless oil. ${ }^{1} \mathrm{H}-\mathrm{NMR}\left(500 \mathrm{MHz}, \mathrm{CDCl}_{3}\right) \delta 1.00(3 \mathrm{H}, \mathrm{t}, J=7.5 \mathrm{~Hz}), 1.28-1.38(12 \mathrm{H}, \mathrm{m}), 1.60-1.66$ (2H, m), 2.15-2.44 (4H, m), $2.42(2 \mathrm{H}, \mathrm{td}, J=7.5,1.5 \mathrm{~Hz}), 5.42-5.47(2 \mathrm{H}, \mathrm{m}), 6.19-6.28(2 \mathrm{H}, \mathrm{m}), 9.77(1 \mathrm{H}, \mathrm{t}$, $J=2.0 \mathrm{~Hz}) ;{ }^{13} \mathrm{C}-\mathrm{NMR}\left(125 \mathrm{MHz}, \mathrm{CDCl}_{3}\right) \delta 202.9,133.6,132.1,123.4,123.0,43.9,29.6,29.4,29.3,29.3$, 29.2, 29.1, 27.4, 22.0, 20.8, 14.2. GC-MS: $t_{\mathrm{R}:} 21.18 \mathrm{~min}$; MS of $\mathbf{1}$ (70 eV, EI): 236.

(11Z,13Z)-hexadecadienol (2): A $100 \mathrm{~mL}$ dried flask was charged with freshly prepared THF (30 mL) under argon and cooled to $0^{\circ} \mathrm{C}$, while $\mathrm{LiAlH}_{4}(760 \mathrm{mg}, 20 \mathrm{mmol})$ was added in portions. A solution of $2.36 \mathrm{~g}$ (10 mmol) of $1 \mathrm{in} 10 \mathrm{~mL}$ THF was added to the flask using a syringe. The resulting mixture was stirred for $30 \mathrm{~min}$ at $0{ }^{\circ} \mathrm{C}$ and then warmed to room temperature. The reaction was monitored using GC until the peak of $\mathbf{1}$ disappeared. The reduction mixture was cooled with an ice bath and treated via the successive dropwise addition of water and 15\% sodium hydroxide solution. The dry granular precipitate was removed via filtration, the filtrate was dried over $\mathrm{Na}_{2} \mathrm{SO}_{4}$, and the solvent was evaporated. The crude material was purified using flash chromatography on silica gel using hexane-ethyl acetate $(15: 1, v / v)$ as an eluent to provide $2.26 \mathrm{~g}(9.5 \mathrm{mmol}, 95 \%$ yield $)$ of 2 as a colorless liquid. ${ }^{1} \mathrm{H}-\mathrm{NMR}\left(500 \mathrm{MHz}, \mathrm{CDCl}_{3}\right) \delta 1.01(3 \mathrm{H}, \mathrm{t}, J=7.5 \mathrm{~Hz}), 1.29-1.40(16 \mathrm{H}, \mathrm{m}), 1.54-1.59(2 \mathrm{H}, \mathrm{m})$, 2.16-2.21 (2H, m), $3.64(2 \mathrm{H}, \mathrm{t}, J=7.5 \mathrm{~Hz}), 5.42-5.48(2 \mathrm{H}, \mathrm{m}), 6.20-6.28(2 \mathrm{H}, \mathrm{m}) ;{ }^{13} \mathrm{C}-\mathrm{NMR}(125 \mathrm{MHz}$, $\left.\mathrm{CDCl}_{3}\right) \delta 133.6,132.1,123.4,123.0,63.1,32.8,29.6,29.6,29.5,29.5,29.4,29.3,27.5,25.7,20.8,14.2$. GC-MS: $t_{\mathrm{R}:} 20.68 \mathrm{~min} ; \mathrm{MS}$ of 2 (70 eV, EI): 238.

(11Z,13Z)-hexadecadienyl acetate (3): A total of $0.47 \mathrm{~g}(6 \mathrm{mmol})$ of pyridine was added to a solution of $1.19 \mathrm{~g}(5 \mathrm{mmol})$ of 2 in $10 \mathrm{~mL}$ of $\mathrm{CH}_{2} \mathrm{Cl}_{2}$ at $0{ }^{\circ} \mathrm{C}$, followed by $0.61 \mathrm{~g}(6 \mathrm{mmol})$ of acetic anhydride. The mixture was stirred for $4 \mathrm{~h}$ and washed with water. The organic was then concentrated to remove the solvent, and the crude was purified using flash chromatography on silica gel using hexane-ethyl acetate $(30: 1, v / v)$ as an eluent to provide $1.37 \mathrm{~g}(4.9 \mathrm{mmol}, 98 \%)$ of 3 as a colorless liquid. ${ }^{1} \mathrm{H}-\mathrm{NMR}$ $\left(500 \mathrm{MHz} \mathrm{CDCl}_{3}\right) \delta 1.01(3 \mathrm{H}, \mathrm{m}), 1.31(16 \mathrm{H}, \mathrm{m}), 1.62(2 \mathrm{H}, \mathrm{m}), 2.04(3 \mathrm{H}, \mathrm{s}), 2.16-2.19(2 \mathrm{H}, \mathrm{m}), 4.05(2 \mathrm{H}$, $\mathrm{t}, J=6.5 \mathrm{~Hz}), 5.42-5.47(2 \mathrm{H}, \mathrm{m}), 6.21-6.28(2 \mathrm{H}, \mathrm{m}) ;{ }^{13} \mathrm{C}-\mathrm{NMR}\left(125 \mathrm{MHz}, \mathrm{CDCl}_{3}\right) \delta 171.3,133.6,132.1$, 123.4, 123.0, 64.7, 32.9, 29.7, 29.6, 29.5, 29.5, 29.3, 29.3, 28.6, 27.5, 25.9, 21.0, 14.2. GC-MS: $t_{\mathrm{R}:} 21.97 \mathrm{~min}$; MS of 3 (70 eV, EI): 280.

(Z)-13-hexadecen-11-ynal (4): A solution of 7 (3.1 g, $15 \mathrm{mmol})$ in tetrahydrofuran $(20 \mathrm{~mL})$ was added to a solution of oxalic acid dihydrate $(3.0 \mathrm{~g})$ in water $(10 \mathrm{~mL})$. The mixture was stirred and heated for $40 \mathrm{~min}$ at $60^{\circ} \mathrm{C}$ under argon. Then, the mixture was extracted with hexane. The organic solution was washed with water, a sodium hydrogen carbonate solution, and brine; dried $\left(\mathrm{Na}_{2} \mathrm{SO}_{4}\right)$; and concentrated in vacuo. The residue was chromatographed over $\mathrm{SiO}_{2}$ with hexane/EtOAc (30:1, $v / v)$, which gave $4(2.24 \mathrm{~g}, 95 \%)$ as a colorless oil. ${ }^{1} \mathrm{H}-\mathrm{NMR}\left(500 \mathrm{MHz}, \mathrm{CDCl}_{3}\right) \delta 1.00(3 \mathrm{H}, \mathrm{t}, J=7.5 \mathrm{~Hz})$, 1.28-1.38 (12H, m), 1.60-1.66 (2H, m), 2.15-2.44 (4H, m), $2.42(2 \mathrm{H}, \mathrm{td}, J=7.5,1.5 \mathrm{~Hz}), 5.42-5.47(1 \mathrm{H}, \mathrm{m})$, 6.19-6.28 (1H, m), $9.77(1 \mathrm{H}, \mathrm{t}, J=2.0 \mathrm{~Hz}) ;{ }^{13} \mathrm{C}-\mathrm{NMR}\left(125 \mathrm{MHz}, \mathrm{CDCl}_{3}\right) \delta 202.9,133.6,132.1,123.4,123.0$, 43.9, 29.6, 29.4, 29.3, 29.3, 29.2, 29.1, 27.4, 22.0, 20.8, 14.2. GC-MS: $t_{\mathrm{R}:} 21.83$ min; MS of 4 (70 eV, EI): 234.

\section{Conclusions}

Based on a C10 + C3 + C3 strategy, facile and efficient syntheses of (11Z,13Z)-hexadecadienal (1), alcohol (2), corresponding acetate (3), and (Z)-13-hexadecen-11-ynal (4), which are key sex pheromone and attractant components of Notodontidae, were achieved. The key steps were accomplished by the alkylation of lithium alkyne, a cis-Wittig olefination reaction, and hydroboration-protonolysis. In addition, (11Z,13Z)-hexadecadienal (1) was also identified as the sex pheromone component of navel orangeworm, Amyelois transitella (Pyralidae) [13], which has become a key pest of tree nuts in California [37,38]. Additionally, for the meal moth Pyralis farinalis, a blend of $(11 Z, 13 Z)$-hexadecadienal (1) and (3Z,6Z,9Z,12Z,15Z)-tricosapentaene acts as the attractant, while (11Z,13Z)-hexadecadien-1-yl 
acetate (3) is a behavioral antagonist [39,40]. This simple, convenient, and efficient synthetic route will be greatly helpful for the further practical testing and the use of pheromones as benign environmental tools for the pest control of Notodontidae and Pyralidae.

Supplementary Materials: The following are available online. GC data for compounds 1, 2, 3, and 4; NMR spectra for all synthetic compounds.

Author Contributions: F.L. performed the experiments and analyzed the data. F.L. wrote the manuscript and corrected it. X.K. participated in the formal analysis. S.Z. participated in the data curation and supervised part of the synthesis. Z.Z. supervised and coordinated all studies and corrected the manuscript. All authors read and approved the final manuscript.

Acknowledgments: We thank the Institute Special Fund for Basic Research, Institute of Forest Ecology, Environment, and Protection, Chinese Academy of Forestry (CAFYBB2016SY017); the Beijing Natural Science Foundation (6194044); and the Special Fund for Basic Scientific Research of Central Public Research Institutes (CAFYBB2016QA008) for financial support. We are very grateful to Ru-Hua Li for his help in GC-MS testing.

Conflicts of Interest: The authors declare no conflict of interest.

\section{References}

1. Van Nieukerken, E.J. Order Lepidoptera Linnaeus, 1758. Zootaxa 2011, 3148, 212-221. [CrossRef]

2. Ando, T.; Inomata, S.I.; Yamamoto, M. Lepidopteran sex pheromones. Top. Curr. Chem. 2004, 239, 51. [PubMed]

3. Roelofs, W.L.; Comeau, A. Sex attractants in Lepidoptera. Chem. Releas. Insects 1971, 91-112.

4. Frérot, B.; Malosse, C.; Milat, M.L.; Demolin, G.; Martin, J.C.; Khemici, M.; Zamoun, M.; Gach, M. Chemical analysis of the sex pheromone glands of Thaumetopoea bonjeani (Powell) (Lep., Thaumetopoeidae). J. Appl. Entomol. 1990, 109, 210-212. [CrossRef]

5. Guerrero, A.; Camps, F.; Coll, J.; Riba, M.; Einhorn, J.; Descoins, C.; Lallemand, J.Y. Identification of a potential sex pheromone of the processionary moth Thaumetopoea pityocampa (Lepitoptera, Notodontidae). Tetrahedron Lett. 1981, 22, 2013-2016. [CrossRef]

6. Halperin, J. Mating disruption of the pine processionary caterpillar by pityolure. Phytoparasitica 1985, 13, 221-224. [CrossRef]

7. Breuer, M.; Kontzog, H.G.; Loof, A.D. The sex attractant pheromone of the oak processionary, Thaumetopoea processionea a field evaluation. Commun. Agric. Appl. Biol. Sci. 2003, 68 Pt A, 203-208.

8. Silk, P.; Lonergan, G.; Allen, D.; Spear-O'mara, J. Potential sex pheromone components of the saddled prominent (Lepidoptera: Notodontidae). Can. Entomol. 2000, 132, 681-684. [CrossRef]

9. Bestmann, H.J.; Kern, F.; Schäfer, D.; Vostrowsky, O.; Hasenfuss, I. (11Z,13Z)-11,13-hexadecadienyl acetate, the sex pheromone of females of Notodonta torva. Naturwissenschaften 1991, 78, 465-467. [CrossRef]

10. Bestmann, H.J.; Kern, F.; Schaefer, D.; Vostrowsky, O. (11Z,13Z)-11,13-hexadecadienal, the sex pheromone of females of Notodonta dromedarius. Naturwissenschaften 1993, 24, 271-273. [CrossRef]

11. Zhang, H.-Y.; Kong, X.-B.; Zhang, Z.; Jing, Y.-J. Study Status of Notodontid (Notodontidae, Lepidoptera) Sex Pheromones. Chin. Agric. Bull. 2007, 23, 477-482.

12. Ando, T.; Inomata, S.I.; Yamamoto, M. Lepidopteran sex pheromones. In The Chemistry of Pheromones and Other Semiochemicals I; Schulz, S., Ed.; Springer: Berlin/Heidelberg, Germany, 2004; pp. 51-96.

13. Coffelt, J.A.; Vick, K.W.; Sonnet, P.E.; Doolittle, R.E. Isolation, identification, and synthesis of a female sex pheromone of the navel orangeworm, Amyelois transitella (Lepidoptera: Pyralidae). J. Chem. Ecol. 1979, 5, 955-966. [CrossRef]

14. Sonnet, P.E.; Heath, R.R. Stereospecific synthesis of (Z,Z)-11,13-hexadecadienal, a female sex pheromone of the navel orangeworm, Amyelois transitella (Lepidoptera: Pyralidae). J. Chem. Ecol. 1980, 6, 221-228. [CrossRef]

15. Michelot, D. Highly stereoselective synthesis of acetates of mono-and diunsaturated alcohols and analogous aldehydes, components of Lepidopteran sex pheromones, using tetrakis [triphenylphosphine]-palladium. Synthesis 1983, 2, 130-134. [CrossRef]

16. Arai, K.; Ando, T.; Sakurai, A.; Yamada, H.; Koshihara, T.; Takahashi, N. Identification of the female sex pheromone of the cabbage webworm. Agri. Biol. Chem. 1982, 46, 2395-2397.

17. Bishop, C.E.; Morrow, G.W. Synthesis of $(Z, Z)-11,13$-hexadecadienal, a principal component of navel orangeworm (Pamyelois transitella) pheromone. J. Org. Chem. 1983, 48, 657-660. [CrossRef] 
18. Gardette, M.; Jabri, N.; Alexakis, A.; Normant, J.F. General methodology for the synthesis of conjugated dienic insect sex pheromones. Tetrahedron 1984, 40, 2741-2750. [CrossRef]

19. Furber, M.; Taylor, R.J.; Burford, S.C. Z,Z-dienes via acetylene carbocupration: Synthesis of navel orangeworm pheromone. Tetrahedron Lett. 1985, 26, 3285-3288. [CrossRef]

20. Furber, M.; Taylor, R.J.; Burford, S.C. Stereospecific diene synthesis using acetylene carbocupration; preparation of navel orangeworm pheromone and leukotriene analogues. J. Chem. Soc. Perk. Trans. 1 1986, 1809-1815. [CrossRef]

21. Cabezas, J.A.; Oehlschlager, A.C. Stereospecific synthesis of (E,Z)-and (Z,Z)-hexadeca-10,12-dienal. Sex pheromone components of Diaphania hyalinata. Synthesis 1999, 1, 107-111. [CrossRef]

22. Mori, K. New synthesis of $(11 Z, 13 Z)-11,13$-hexadecadienal, the female sex pheromone of the navel orangeworm. Biosci. Biotechnol. Biochem. 2009, 73, 2727-2730. [CrossRef]

23. Camps, F.; Coll, J.; Guerrero, A.; Riba, M. Simple and stereoselective synthesis of sex pheromone of processionary moth Thaumetopoea pityocampa (Denis and Schiff.). J. Chem. Ecol. 1983, 9, 869-875. [CrossRef] [PubMed]

24. Gardette, M.; Alexakis, A.; Normant, J.F. Synthesis of (Z)-13-hexadecen-11-yn-1-yl acetate Major component of sex pheromone of the processionary moth. J. Chem. Ecol. 1983, 9, 219-223. [CrossRef]

25. Ando, T.; Kurotsu, Y.; Kaiya, M.; Uchiyama, M. Systematic syntheses and characterization of dodecadien-1-ols with conjugated double bond, lepidopterous sex pheromones. Agri. Biol. Chem. 1985, 49, 141-148. [CrossRef]

26. Kaiser, A.; Marazano, C.; Maier, M. First synthesis of marine sponge alkaloid niphatoxin B. J. Org. Chem. 1999, 64, 3778-3782. [CrossRef] [PubMed]

27. Sabitha, G.; Reddy, E.V.; Bhikshapathi, M.; Yadav, J.S. Total synthesis of $(9 S, 12 R, 13 S)$-pinellic acid. Tetrahedron Lett. 2007, 48, 313-315. [CrossRef]

28. Millar, J.G.; Knudson, A.E.; McElfresh, J.S.; Gries, R.; Gries, G.; Davis, J.H. Sex attractant pheromone of the pecan nut casebearer (Lepidoptera: Pyralidae). Bioorgan. Med. Chem. 1996, 4, 331-339. [CrossRef]

29. Santangelo, E.M.; Coracini, M.; Witzgall, P.; Correa, A.G.; Unelius, C.R. Identification, syntheses, and characterization of the geometric isomers of 9,11-hexadecadienal from female pheromone glands of the sugar cane borer Diatraea saccharalis. J. Nat. Prod. 2002, 65, 909-915. [CrossRef]

30. Löfstedt, C.; Zhu, J.; Kozlov, M.V.; Buda, V.; Jirle, E.V.; Hellqvist, S.; Löfqvist, J.; Plass, E.; Franke, S.; Francke, W. Identification of the sex pheromone of the currant shoot borer Lampronia capitella. J. Chem. Ecol. 2004, 30, $643-658$. [CrossRef]

31. Tsuboi, S.; Ishii, N.; Sakai, T.; Tari, I.; Utaka, M. Oxidation of Alcohols with Electrolytic Manganese Dioxide. Its Application for the Synthesis of Insect Pheromones. B Chem. Soc. Jpn. 1990, 63, 1888-1893. [CrossRef]

32. Ragoussis, V.; Perdikaris, S.; Karamolegkos, A.; Magkiosi, K. Improved synthesis of (3E,7Z)-3,7-Tetradecadienyl Acetate, the major sex pheromone constituent of the potato pest Symmetrischema tangolias (Gyen). J. Agric. Food. Chem. 2008, 56, 11929-11932. [CrossRef]

33. Khrimian, A.; Lance, D.R.; Mastro, V.C.; Elkinton, J.S. Improved Synthesis of (3E,6Z,9Z)-1,3,6,9-Nonadecatetraene, Attraction Inhibitor of Bruce Spanworm, Operophtera bruceata, to Pheromone Traps for Monitoring Winter Moth, Operophtera brumata. J. Agric. Food. Chem. 2010, 58, 1828-1833. [CrossRef] [PubMed]

34. Bercot, E.A.; Stoltz, B.M. Method of preparing Z-Alkene-Containing Insect Pheromones. Patent No. 9,181,164, 10 November 2015.

35. Khrimian, A.; Klun, J.A.; Hijji, Y.; Baranchikov, Y.N.; Pet'ko, V.M.; Mastro, V.C.; Kramer, M.H. Syntheses of $(Z, E)$-5,7-dodecadienol and (E,Z)-10,12-hexadecadienol, Lepidoptera pheromone components, via zinc reduction of enyne precursors. Test of pheromone efficacy against the Siberian moth. J. Agric. Food. Chem. 2002, 50, 6366-6370. [CrossRef]

36. Hungerford, N.L.; Kitching, W. Titanium (II)-based Z-reduction of alkynes. Syntheses of deuterium labelled linolenic and oleic acids and (3E,8Z,11Z)-tetradeca-3,8,11-trienyl acetate, the sex pheromone of a tomato pest, Scrobipalpuloides absoluta. J. Chem. Soc. Perk. Trans. 1 1998, 11, 1839-1858. [CrossRef]

37. Palumbo, J.D.; Mahoney, N.E.; Light, D.M. Navel orangeworm (Amyelois transitella) as a vector of Aspergillus flavus on almonds. Phytopathology 2008, 98, S119.

38. Beck, J.J.; Higbee, B.S.; Light, D.M.; Gee, W.S.; Merrill, G.B.; Hayashi, J.M. Hull split and damaged almond volatiles attract male and female navel orangeworm moths. J. Agric. Food. Chem. 2012, 60, 8090-8096. [CrossRef] [PubMed] 
39. Leal, W.S.; Parra-Pedrazzoli, A.L.; Kaissling, K.E.; Morgan, T.I.; Zalom, F.G.; Pesak, D.J.; Dundulis, E.A.; Burks, C.S.; Higbee, B.S. Unusual pheromone chemistry in the navel orangeworm: Novel sex attractants and a behavioral antagonist. Naturwissenschaften 2005, 92, 139-146. [CrossRef] [PubMed]

40. Kanno, H.; Kuenen, L.P.S.; Klingler, K.A.; Millar, J.G.; Cardé, R.T. Attractiveness of a four-component pheromone blend to male navel orangeworm moths. J. Chem. Ecol. 2010, 36, 584-591. [CrossRef]

Sample Availability: Samples of the compounds from $\mathbf{1}$ to $\mathbf{7}$ are available from the authors.

(C) 2019 by the authors. Licensee MDPI, Basel, Switzerland. This article is an open access article distributed under the terms and conditions of the Creative Commons Attribution (CC BY) license (http://creativecommons.org/licenses/by/4.0/). 